\title{
Isolation and preliminary characterization of pig primordial follicles
}

\author{
G. S. Greenwald* and R. M. Moor $\dagger$ \\ * Department of Physiology, University of Kansas Medical Center, Kansas City, KS 66103, USA; \\ and $\dagger$ Department of Molecular Embryology, Institute of Animal Physiology and Genetics Research, \\ Babraham, Cambridge CB2 4AT, UK
}

\begin{abstract}
Summary. An enzymic method for recovering primordial follicles from the pig ovary consists of incubating cortical slices for $2 \mathrm{~h}$ with $0.025 \%$ collagenase $1 \mathrm{~A}$. An average of 185000 or 419000 primordial follicles per ovary were recovered from ovaries collected in Cambridge and Kansas, respectively. Following a discontinuous Percoll gradient, primordial follicles can be separated from contaminating somatic cells by mouth pipette or a micromanipulator to collect 100-1500 follicles but for large scale recovery of approximately 30000 follicles flow cytometry is recommended. Two types of primordial follicles can be distinguished by electron microscopy: peripheral clusters of small oocytes with an incomplete investment of pregranulosa cells and a deeper region of individual oocytes surrounded by a complete layer of pregranulosa cells. The viability of the purified primordial follicles is attested by their ability to synthesize proteins for at least $12 \mathrm{~h}$ after incubation with $\left[{ }^{35} \mathrm{~S}\right]$ methionine. Moreover, the primordial follicles showed several polypeptide bands in common with mature oocytes especially with $M_{\mathrm{r}}$ of $60000-90000$ but with considerable differences from somatic cells.
\end{abstract}

Keywords: primordial follicles; structure; protein synthesis; enzymic dissociation; pig

\section{Introduction}

In a series of recent papers, we have established the feasibility of isolating intact preantral follicles from the hamster ovary which opens this relatively unexplored population to descriptive and experimental analyses (for references, see Roy \& Greenwald, 1988). Knowledge of primordial follicles is even more limited, mainly to changes in numbers with age (for references, see Gougeon \& Chainy, 1987), species differences (Gosden \& Telfer, 1987) and ultrastructural observations (Baca \& Zamboni, 1967). As a logical extension, the present paper describes successful attempts to develop similar methodology to recover primordial follicles and separate them from contaminating somatic cells. The pig ovary was selected because of its large number of primordial follicles (Gosden \& Telfer, 1987) and the ready availability of abattoir-derived material.

\section{Materials and Methods}

Source of ovaries. Pig ovaries were collected from abattoirs in Cambridge (Large White breed) or Oskaloosa, KS (2- or 3-way crosses between Yorkshire, Hampshire or Duroc lines). Where necessary, source of ovaries will be designated as Cambridge or Kansas. All ovaries used in the UK were at ambient temperature when delivered to the laboratory. Because of the greater distances involved $(80 \mathrm{~km})$, ovaries collected in Kansas were brought to the laboratory on ice or in a thermos containing physiological saline at room temperature. For the latter ovaries, the profile of incorporation of $\left[{ }^{35}\right.$ S $]$ methionine into protein by primordial follicles collected by enzymic dissociation was unaffected by temperature whereas oocytes recovered by aspiration from mature follicles $(3-6 \mathrm{~mm})$ only gave satisfactory results at room temperature; transport on ice was highly deleterious to protein synthesis by the mature oocytes. 
Enzymic dissociation of ovaries. Ovaries preferably lacking corpora lutea and with antral follicles $<3 \mathrm{~mm}$ in diameter were used; these ovaries correspond to the "honey-comb" variety described by Dufour et al. (1985). After severing blood vessels as close to the hilum as possible, the ovaries were rinsed several times in normal saline $(0 \cdot 154 \mathrm{M}$ $\mathrm{NaCl}$ ) before removing the cortex which contained the primordial, as well as larger, follicles. The cortical sections were then minced into small pieces $(2-3 \mathrm{~mm})$. The equivalent of one ovary was incubated in $10 \mathrm{ml} 0.025 \%$ collagenase

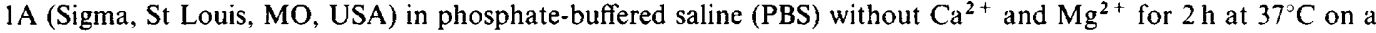
rocking platform set at $50 \mathrm{rev} / \mathrm{min}$. The medium was filtered through a $64 \mu \mathrm{m}$ nylon mesh filter into a conical tube; about $30-40 \%$ of the primordial follicles were recovered from this fraction. The remainder were recovered by flushing the tissue slices with $10 \mathrm{ml}$ PBS through a $64 \mu \mathrm{m}$ filter. The two fractions were centrifuged at $600 \mathrm{~g}$ for $5 \mathrm{~min}$, the PBS was decanted and each fraction was reconstituted in $1 \mathrm{ml}$ PBS. The contents were then combined and passed through a $64 \mu \mathrm{m}$ filter. At this step, the number of primordial follicles was usually counted with a haemocytometer. The primordial follicles were easily recognized by their size and dark appearance compared to somatic cells. To determine how many of the primordial follicles were covered with pregranulosa cells, whole mounts of approximately 100 follicles (from Kansas ovaries) were stained with 1\% lacmoid (Parkening \& Cisneros, 1988). The results reported in this paper were based on $\sim 200$ ovaries.

Percoll separation of primordial follicles. A discontinuous Percoll gradient (Pharmacia, Uppsala, Sweden) of $2 \mathrm{ml}$ of $20 \%, 40 \%, 60 \%, 80 \%$ was prepared with $0 \cdot 15 \mathrm{M}-\mathrm{NaCl} 1-2 \mathrm{~h}$ before use. The enzymically dissociated contents of one ovary were diluted to $4 \mathrm{ml}$ and $2 \mathrm{ml}$ were loaded on top of the $8-\mathrm{ml}$ gradient (therefore 2 tubes per ovary). The tubes were centrifuged at $2100 \mathrm{~g}$ for $15 \mathrm{~min}$ in a centrifuge with swinging bucket rotors (Cambridge: MSE Super Minor; Kansas: Damon, model 6000) and $1 \mathrm{ml}$ fractions were collected. Most of the primordial follicles were recovered from the 4th sample (see 'Results'). Therefore, the 4th fraction from one or two ovaries was pooled, brought up to $10 \mathrm{ml}$ with PBS, centrifuged at $300 \mathrm{~g}$ for $5 \mathrm{~min}$, resuspended in $2 \mathrm{ml} \mathrm{PBS}$ and passed through a $35 \mu \mathrm{m}$ nylon mesh filter before being subjected to flow cytometry for cell sorting.

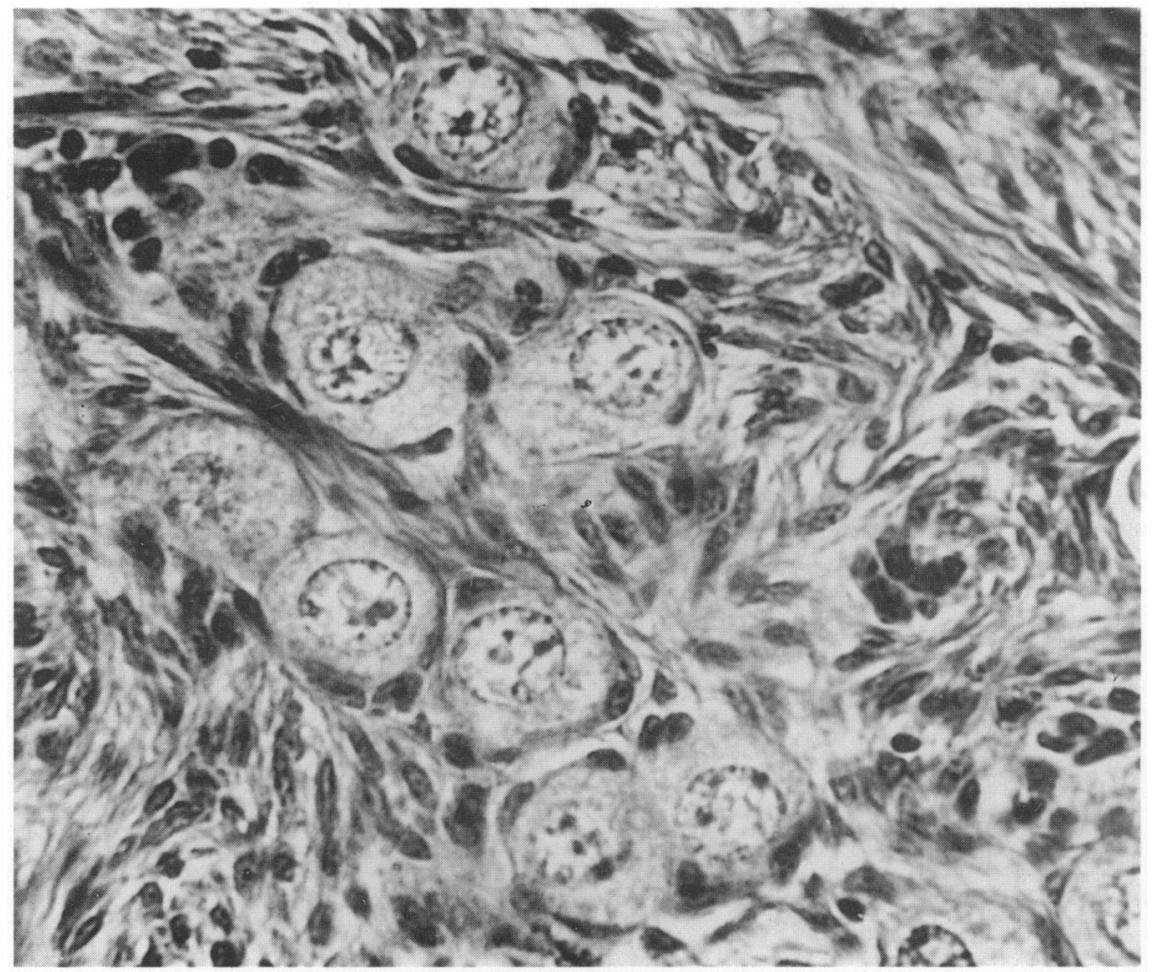

Fig. 1. Photomicrograph of primordial follicles located in the tunica albuginea at the periphery of the pig ovary. Note the incomplete covering of pregranulosa cells and the intimate contact between the oocytes. $\times 400$. 


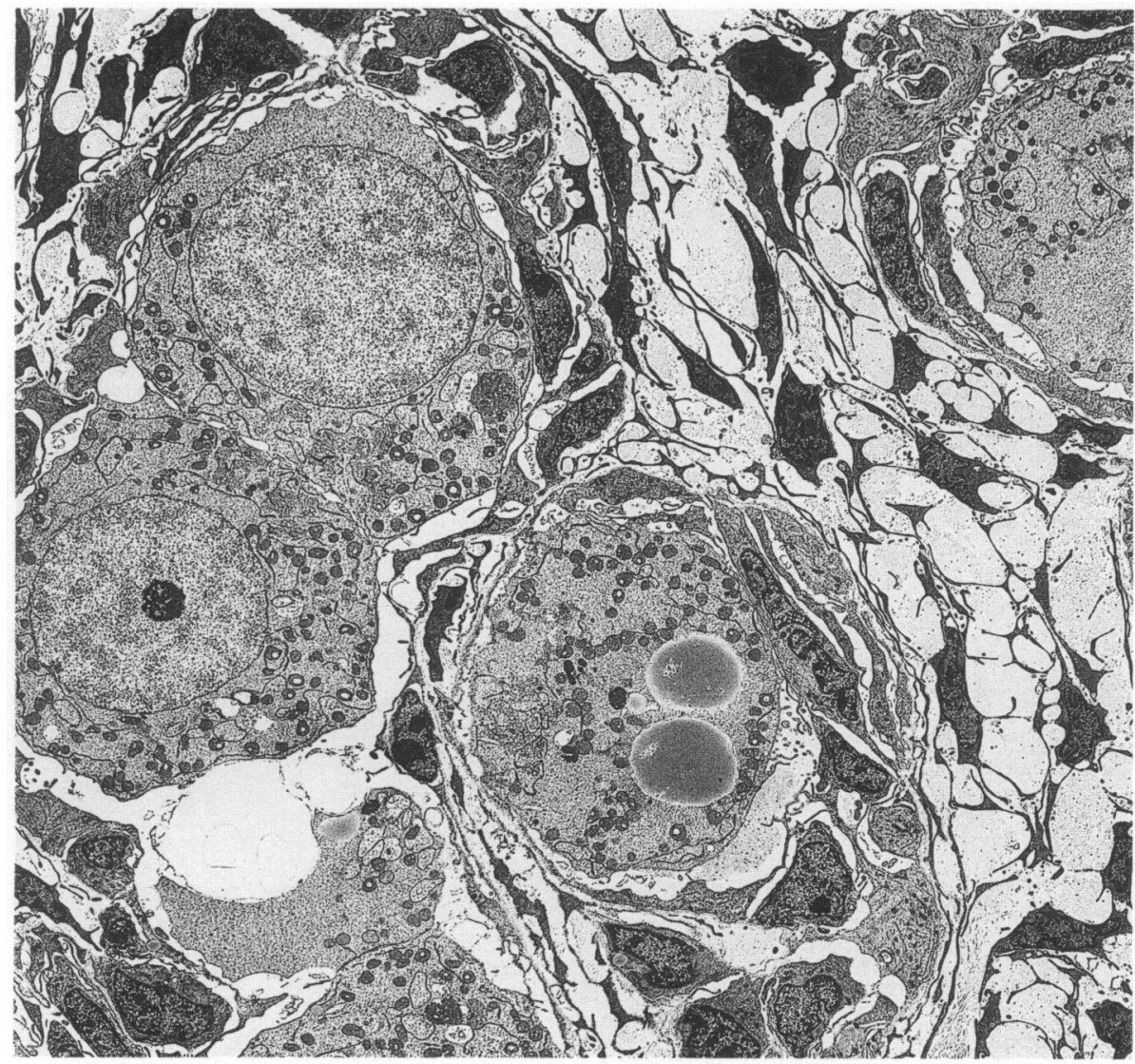

Fig. 2. Electron micrograph of a 'nest' of primordial follicles. Note juxtaposed oocytes without intervening pregranulosa cells and the abundant mitochondria. $\times 2040$.

Flow cytometry. Samples were sorted in a FACS 420 cell sorter (Becton Dickinson FACS Systems, Sunnyvale, CA, USA) equipped with a $70 \mu \mathrm{m}$ flow nozzle and using the $488 \mathrm{~nm}$ argon laser line at $400 \mathrm{~mW}$ with forward light scattering for $30-40 \mathrm{~min}$. Two sorting windows were used: an extreme left sort to collect somatic cells and a right sort to recover purified primordial follicles.

Electrophoretic separation of polypeptides. Protein profiles were examined in oocytes at the primordial and antral stages of development. After enzymic digestion, oocytes from primordial follicles were separated from contaminating somatic cells using both FACS and manual separation techniques. Groups of 500-30000 primordial follicles were placed in $50 \mu \mathrm{l}$ drops of MEM (methionine-free) supplemented with BSA ( $4 \mathrm{mg} / \mathrm{ml}$ ), insulin ( $35 \mu \mathrm{g} / \mathrm{ml}$ ), ascorbic acid and $\mathrm{L}-\left[{ }^{35} \mathrm{~S}\right]$ methionine (sp. act. $>1000 \mathrm{Ci} / \mathrm{mmol}$ : Amersham International, Amersham, Bucks, UK). Incubations were carried out at $39^{\circ} \mathrm{C}$ for 6 or $12 \mathrm{~h}$ with $\left.500 \mu \mathrm{Ci}{ }^{35} \mathrm{~S}\right]$ methionine/ml in an atmosphere of $5 \% \mathrm{CO}_{2}$ in air. For comparative purposes, pooled follicle cells recovered by enzymic dissociation from preantral and antral follicles were similarly radiolabelled. At the end of the labelling period, the oocytes or somatic (i.e. follicle) cells were briefly washed with $0.01 \mathrm{M}$-Tris- $\mathrm{HCl}, \mathrm{pH} 7 \cdot 4$, collected in $3 \mu \mathrm{l}$ Tris buffer and frozen at $-80^{\circ} \mathrm{C}$ until required for electrophoresis.

The preparation of cells for electrophoresis and the determination of the incorporation of radioactivity into TCAprecipitable material was carried out using procedures previously described (Moor et al., 1981). Equal numbers of TCA-precipitable c.p.m. were applied to individual wells of an 8-15\% linear gradient SDS-polyacrylamide slab gel (Laemmli, 1970). Fluorography was carried out using the techniques of Bonner \& Laskey (1974) and densitometric analyses were performed on a Chromoscan 3 (Joyce Lobel, Marquisway, UK) or a Bio Rad 620 video-densitometer attached to an IBM-AT mircrocomputer (USA).

Ovarian morphology. An ovary collected at Cambridge was sectioned serially at $10 \mu \mathrm{m}$ with every 10 th section mounted and stained with haematoxylin and eosin. After enzymic dissociation, primordial follicles were photographed with bright-field illumination with a Nikon Diaphot inverted microscope. Additional ovaries (from Kansas) for ultrastructural study were prepared and sectioned by the KUMC Electron Microscopy Research Center. 


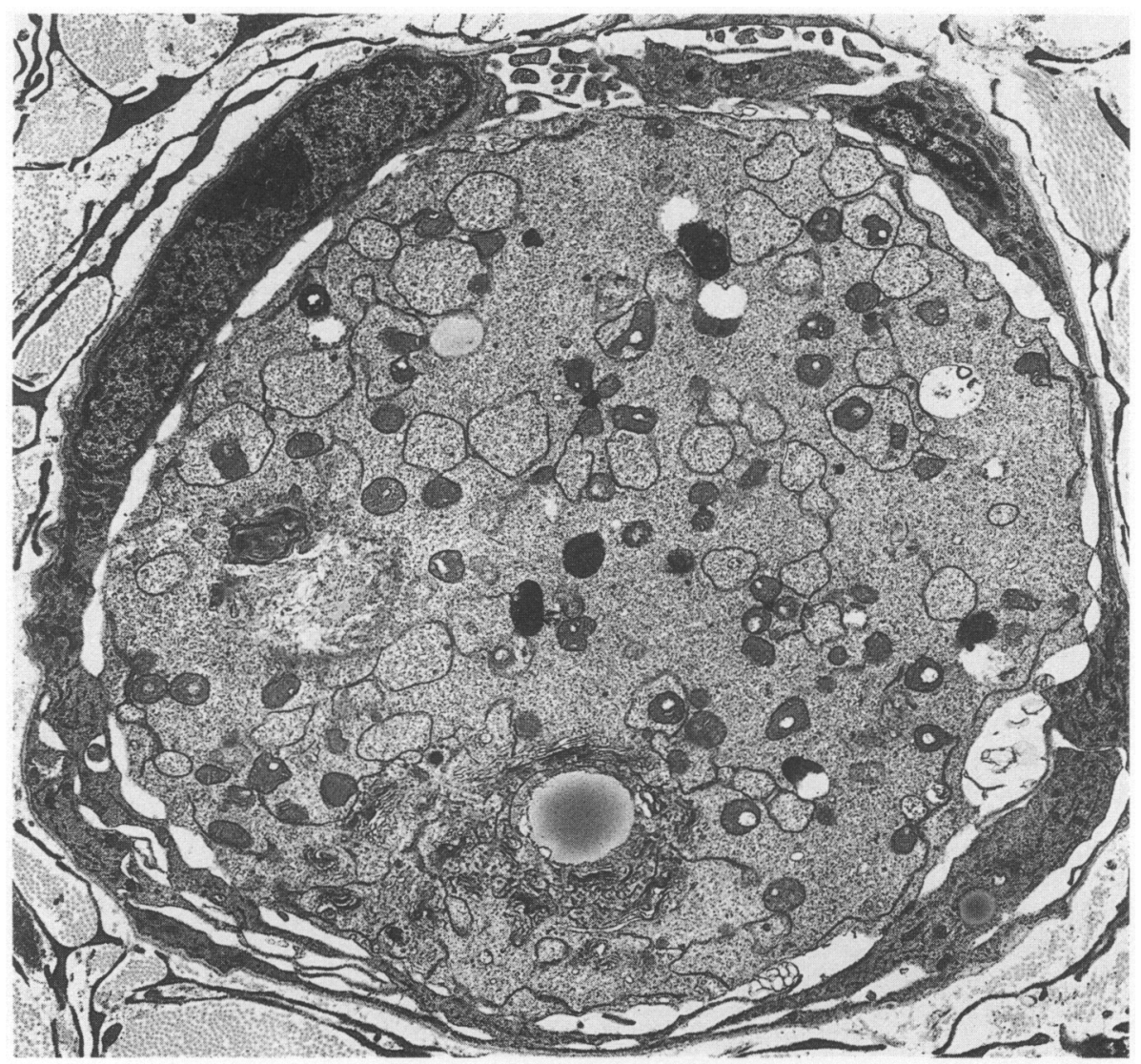

Fig. 3. Electron micrograph of a primordial follicle located farther away from the germinal epithelium. The numerous mitochondria and well developed endoplasmic reticulum are evident. $\times 5220$.

\section{Results}

\section{Morphology of primordial follicles}

The primordial follicles were concentrated at the periphery of the ovary, embedded in the tunica albuginea (Fig. 1). There appeared to be two types: the ones closest to the germinal epithelium were arranged in clusters with an incomplete covering of pregranulosa cells surrounding nests of oocytes, some of which were juxtaposed with no intervening pregranulosa cells. Nearer the centre of the ovary, the primordial follicles were discrete, with each one completely invested with a unilaminar series of spindle-shaped cells.

These observations were confirmed by electron microscopy. There was an intimate relationship between some of the nest-like oocytes with a scanty incomplete covering of pregranulosa cells (Fig. 2). A very rich, scattered mitochondrial population was evident. A primordial follicle, at a deeper level, showed a complete covering of pregranulosal cells which were not adherent along their entire length to the oolemma (Fig. 3). Whether this is an artefact due to shrinkage cannot be ascertained. Numerous mitochondria were randomly distributed with an extensive network of endoplasmic reticulum (ER) permeating the cytoplasm (Fig. 3). At still higher magnifications (not shown) the endoplasmic reticulum consisted of about $25 \%$ rough ER and $75 \%$ smooth ER. 


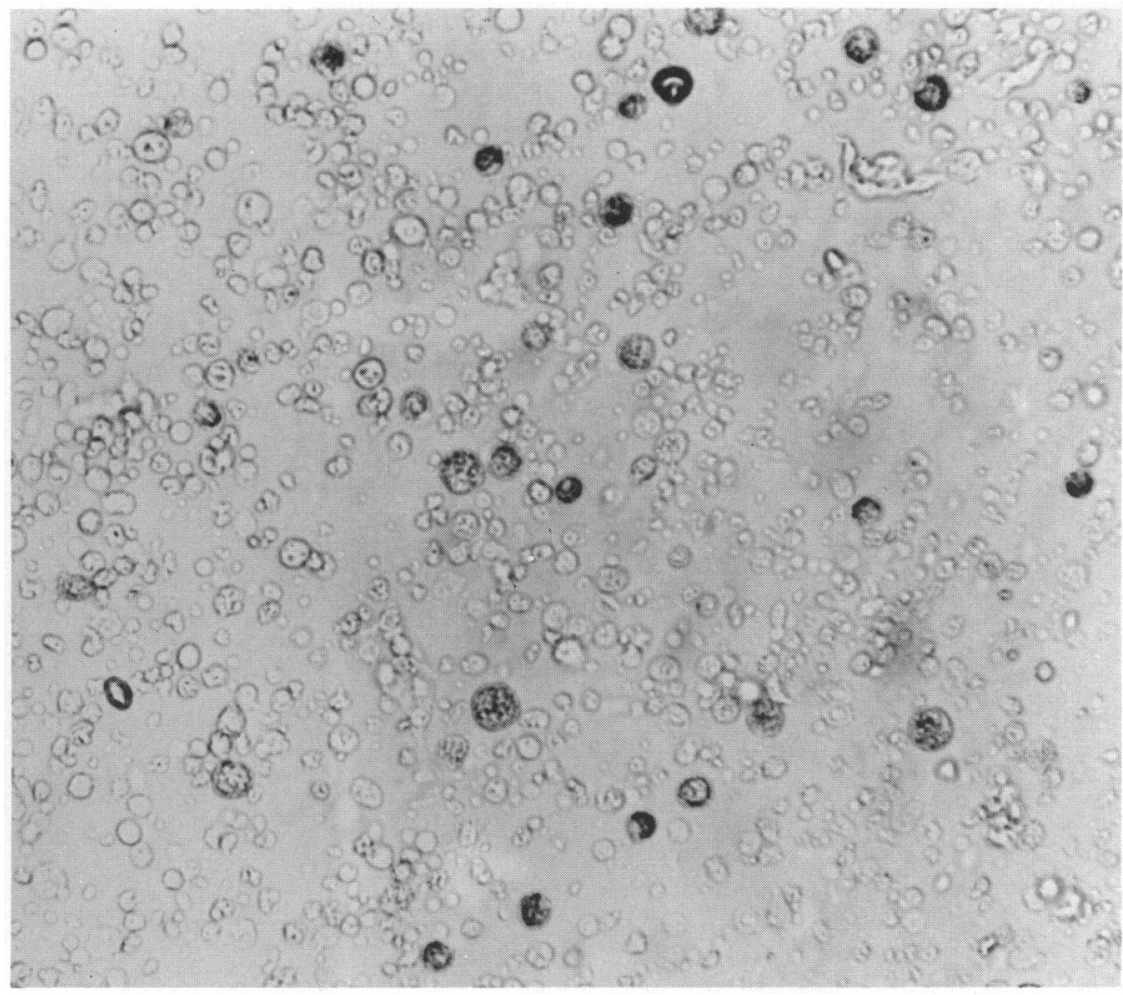

Fig. 4. Primordial follicles after enzymic dissociation. They are distinguishable from somatic cells on the basis of their large size and dark appearance which presumably reflects the abundant presence of mitochondria. $\times 100$.

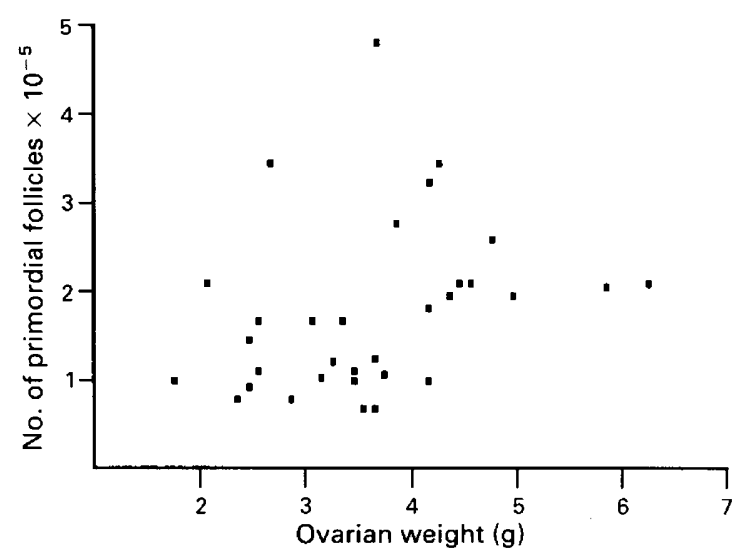

Fig. 5. Ovarian weight versus number of primordial follicles after enzymic dissociation of ovaries collected at Cambridge $(n=32)$. 
Table 1. Mean ( \pm s.e.m.) number of primordial follicles recovered from $1-\mathrm{ml}$ fractions of $10 \mathrm{ml}$ Percoll gradient

\begin{tabular}{lrrrrrrrrrr}
\hline & \multicolumn{10}{c}{ Fraction } \\
\cline { 2 - 10 } & $1 \dagger$ & \multicolumn{1}{c}{2} & \multicolumn{1}{c}{3} & \multicolumn{1}{c}{4} & 5 & 6 & 7 & 8 & 9 & 10 \\
\hline Mean & 0 & 15500 & 20361 & 57100 & 11722 & 0 & 0 & 0 & 0 & 0 \\
s.e.m. & & 2496 & 6547 & 6444 & 4684 & & & & & \\
$\%$ & & 14.8 & 19.5 & 54.5 & 11.2 & & & & & \\
\hline
\end{tabular}

†The uppermost $1-\mathrm{ml}$ layer of the gradient.

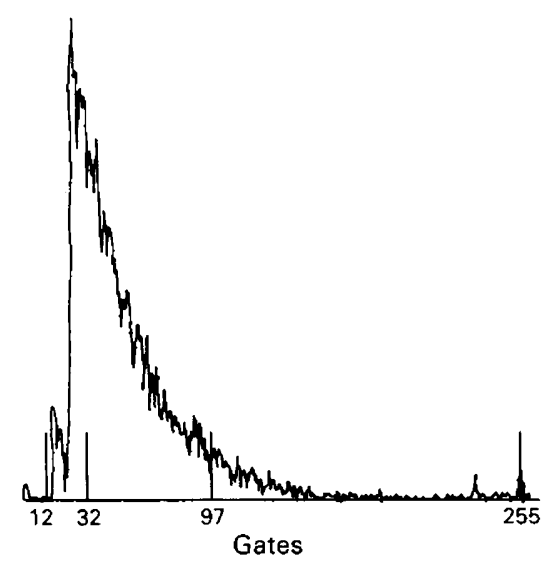

Fig. 6. Histogram of cell size of Percoll-selected cells run on the FACS 420. Gates 12-32 encompassed somatic cells; Gates 97-255 contained only primordial follicles.

After enzymic dissociation of the ovary, the primordial follicles were easily recognized based on their dark appearance, presumably corresponding to the abundant mitochondria (Figs $2 \& 3$ ), and their size relative to the somatic cells (Fig. 4). The primordial follicles averaged $22.1 \pm 0.5 \mu \mathrm{m}$ $(n=116)$ in diameter with a range from 11 to $33 \mu \mathrm{m}$ (an extreme value). They were extremely abundant as exemplified by the ovaries collected at Cambridge (Fig. 5). The regression line relating ovarian weight to number of primordial follicles per ovary $(n=32)$ was $y=0.743+0.293 x$ and the relationship $(r=0 \cdot 31)$ was not significant. The ovaries gathered in Kansas contained even more primordial follicles: an average of $419441 \pm 21031$ (s.e.m.) per ovary $(n=68)$. The regression equation was $y=2.90+0.378 x$ and again with a very weak correlation between ovarian weight and number of primordial follicles $(r=0 \cdot 223)$.

Ovarian histology and ultrastructure showed the rather tenuous relationship between pregranulosa cells and primordial oocytes and it was therefore imperative to establish how many of the isolated oocytes were denuded or still had attached pregranulosa cells. This was accomplished by examining whole mount preparations of primordial follicles stained with lacmoid. After enzymic dissociation of two ovaries, of a total of 55 primordial follicles examined, $75 \%$ were naked oocytes $(n=41), 11 \%$ had $1-3$ adherent pregranulosa cells $(n=6)$ and $14 \%$ had 4 or more attached pregranulosa cells $(n=8)$. An interesting contrast was provided by examining primordial follicles recovered from 2 ovaries by mechanical agitation of cortical slices incubated for $2 \mathrm{~h}$ without collagenase: all 25 oocytes were naked, lacking any pregranulosa cells. The nucleus was easily visualized in denuded primordial oocytes. While $100 \%$ of the primordial oocytes isolated by mechanical agitation were mononucleated $(n=25), 20 \%$ of the enzymically dissociated oocytes were binucleated $(5 / 25)$. 


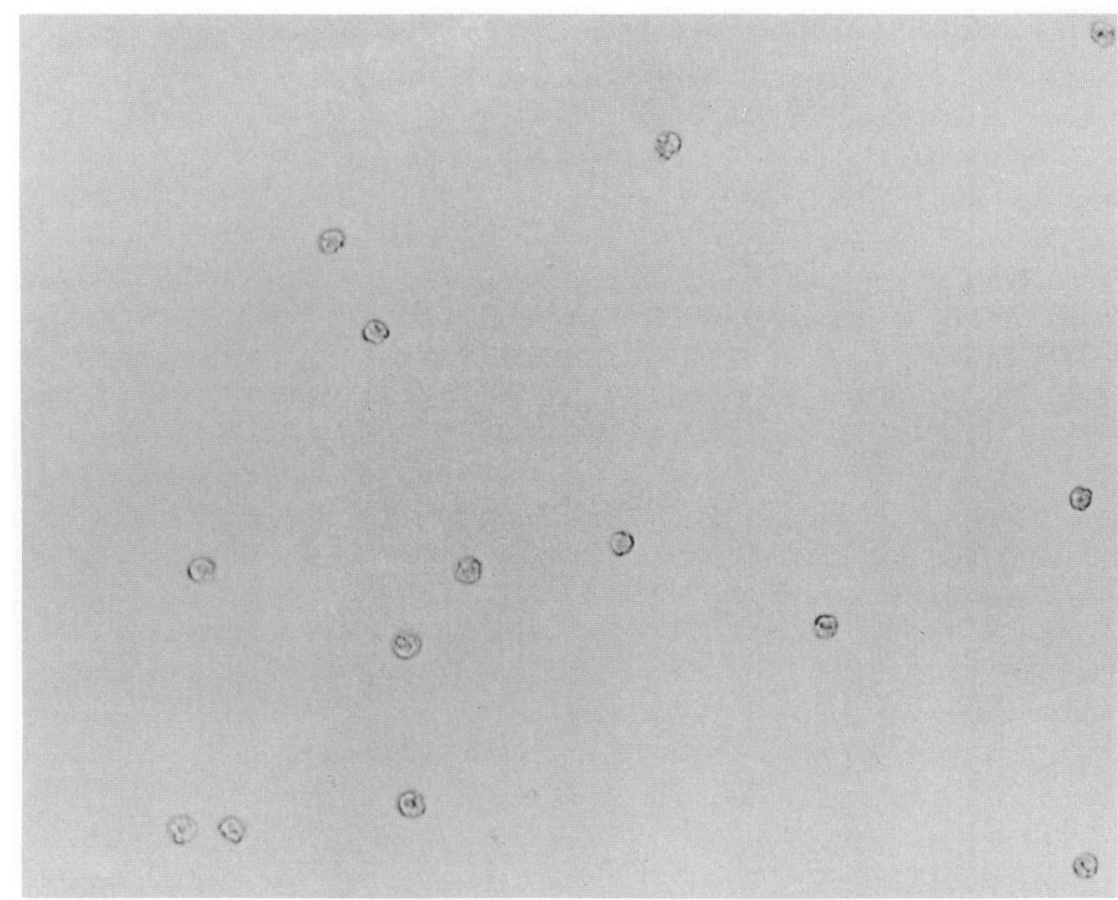

Fig. 7. Preparation of primordial follicles after cell sorting by flow cytometry. Note absence of somatic cells. $\times 100$.

\section{Recovery of primordial follicles from Percoll gradient}

Table 1 summarizes the results of 10 experiments in which a discontinuous Percoll gradient was used to purify the primordial follicles. The experiment was performed at Cambridge. It is evident that fraction 4 contained the majority of primordial follicles. The mean number of primordial follicles recovered from the entire gradient was 104683 compared to 184563 from the enzymic dissociation $(57 \%)$.

\section{Techniques used to separate further primordial follicles from somatic cells}

Several methods have proved satisfactory to recover uncontaminated primordial follicles. For techniques requiring small numbers (100-1500) of primordial follicles, they can be collected by either precalibrated mouth pipettes ( $60 \mu \mathrm{m}$ outer diameter) or by a micromanipulator by a two-step method. For either procedure, after the discontinuous Percoll gradient, an aliquant of fraction 4 was diluted several-fold with PBS; this facilitated the collection of primordial follicles, minimizing contamination by follicle cells. In turn, follicles were sorted from the first collection yielding preparations which were $95-100 \%$ pure primordial follicles. However, these methods are too tedious and time consuming to acquire large numbers. In efforts at Kansas, centrifugal elutriation (Meistrich, 1983) has so far been unsatisfactory because of too high a degree of contamination with somatic cells. At present, cell sorting by flow cytometry is the method of choice for large scale recovery of primordial follicles. Figure 6 shows the results of combining fraction 4 samples (Percoll gradient) from 2 ovaries of $4.83 \times 10^{6}$ cells and a 40 -min run on the flow cytometer. This resulted in clean separation of somatic cells (left sort contained $41 \%$ of total cells) and primordial follicles (constituting $7 \cdot 1 \%$ of cells). There were at least 35000 primordial follicles in the right sort. Figure 7 shows the degree of purity of primordial follicles that can be obtained after flow cytometry. 


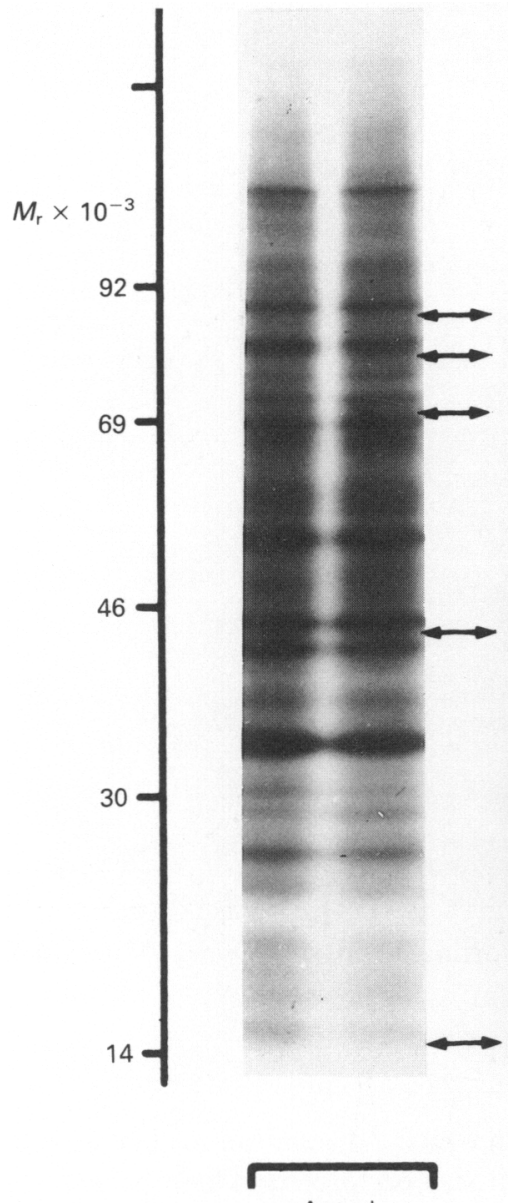

Antral

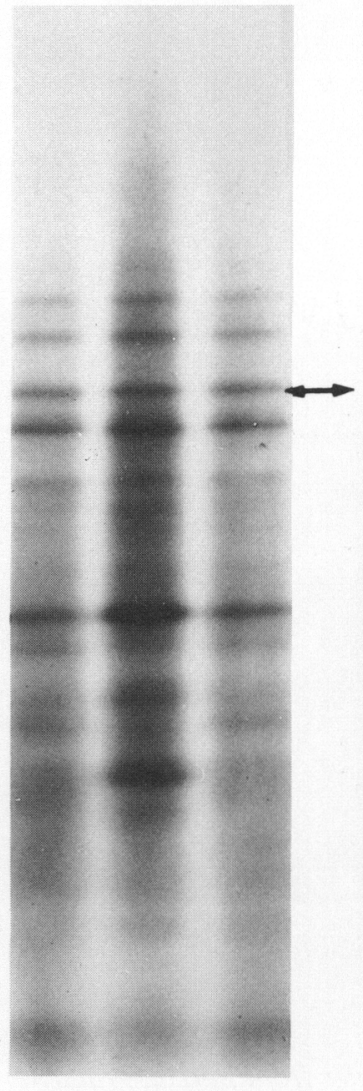

Primordial

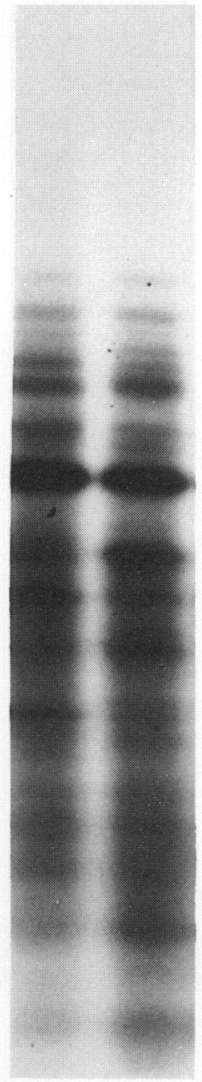

Somatic

Fig. 8. Fluorograph of $\left[{ }^{35} \mathrm{~S}\right]$ methionine-labelled polypeptides (tissue) from oocytes at the germinal vesicle stage obtained from antral or primordial follicles. Also shown is the pattern of polypeptides synthesized by follicle cells (somatic). After manual separation oocytes and somatic cells were cultured for $12 \mathrm{~h}$ before the labelled polypeptides were separated on an 8-15\% SDS-polyacrylamide gel. The arrows show polypeptides in primordial oocytes which have an electrophoretic mobility precisely similar to those synthesized by antral-stage oocytes or follicle cells.

\section{Protein synthesis by primordial follicles}

Amino acid incorporation. The incorporation of $\left[{ }^{35} \mathrm{~S}\right]$ methionine into TCA-precipitable protein by non-growing oocytes from primordial follicles was approximately about $0 \cdot 5-1 \%$ of that of germinal vesicle-stage oocytes from antral follicles. Moreover, individual primordial oocytes manually selected by micropipette after $12 \mathrm{~h}$ labelling incorporated $\sim 50$ c.p.m. $\left[{ }^{35}\right.$ S $]$ methionine into protein as compared with only $2-5$ c.p.m. per oocyte in those selected automatically by cell sorter.

Profile of polypeptide synthesis. The pattern of polypeptide synthesis was very similar between the 15 groups of oocytes obtained from primordial follicles at different stages during the course of the experiments. Neither the duration of labelling $(6 \mathrm{~h} v s 12 \mathrm{~h})$ nor the method of purification (microselection vs FACS-assisted cell sorting) altered the polypeptide profile. A direct comparison between the polypeptides synthesized by oocytes from antral and primordial follicles showed that 

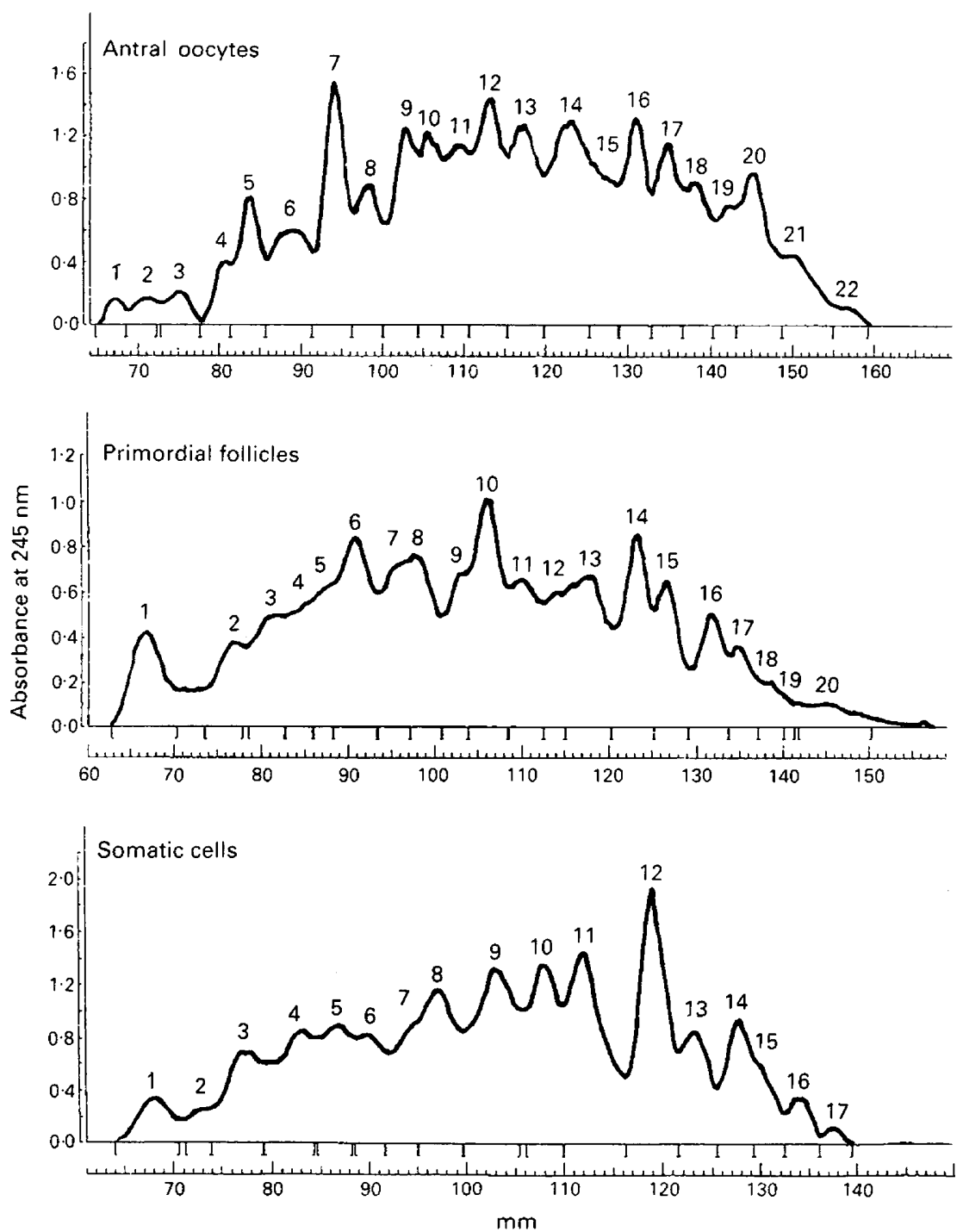

Fig. 9. Densitometric tracing of fluorograph shown in Fig. 8. The top of the gels is at the right end of the tracings.

even the latter group synthesize proteins which are characteristic of fully grown oocytes at the germinal vesicle stage (Fig. 8). The similarities are particularly evident in polypeptides with $M_{\mathrm{r}} 60000-90000$. Equally clear from Fig. 8 is the considerable degree of dissimilarity that exists between the polypeptides synthesized by primordial oocytes and their associated follicle cells. This result is of particular interest since gap junctions already appear to link the oocyte to the adjacent follicle cells at the primordial stage. A densitometric tracing of Fig. 8 shows the similarities and differences of the cell types (Fig. 9).

\section{Discussion}

These experiments establish the feasibility of isolating a pure population of primordial follicles from the mammalian ovary. The technique is especially suitable for species with large numbers of 
primordial follicles such as sheep, pig, cow and human (Gosden \& Telfer, 1987). The number of primordial follicles recovered after enzymic dissociation of pig ovaries collected in Cambridge (185000 per ovary) was in excellent agreement with the number counted in histological sections (420 000 per pair of ovaries) (Gosden \& Telfer, 1987) and even more impressive numbers were harvested from the ovaries available in Kansas. It is possible that strain differences account for the greater number of primordial follicles in the ovaries collected in Kansas.

Light and electron microscopy revealed two types of primordial follicles in the pig ovary: a peripheral zone of clustered oocytes with incomplete investment of pregranulosa cells and a deeper region in which individual follicles were surrounded by a separate layer of pregranulosa cells. It seems quite likely that the latter follicles represent a further step in differentiation and are the forerunners of the primary follicles. A similar heterogeneity has been described for primordial follicles in the guinea-pig (Adams \& Hertig, 1964). Additional evidence substantiating the existence of distinct populations of primordial follicles is provided by the whole mount preparations of enzymically or mechanically dissociated pig follicles. The latter group consisted only of denuded oocytes whereas the former included $25 \%$ oocytes with attached pregranulosa cells. A high percentage of the primordial 'follicles' isolated, by enzymic or mechanical dissociation, consist of naked oocytes. This does not appear to be attributable to the method of separation but rather to the anatomical organization of the peripheral zone of primordial follicles whereby several adhere closely together without intervening pregranulosa cells; the latter are limited to the outer investment of the cords of oocytes (Fig. 1). It is noteworthy that $60-70 \%$ of the oocytes are recovered from the tissue fragments, not from the medium, suggesting that although the collagenase treatment has weakened and dispersed the tunica albuginea the majority of primordial follicles are still loosely attached to the innermost portion of the ovarian cortex.

The ability of the primordial follicles to synthesize proteins in vitro for at least $12 \mathrm{~h}$ attests to their viability. In preliminary experiments, primordial follicles have been incubated for $24 \mathrm{~h}$ or $48 \mathrm{~h}$ with $\left[{ }^{35}\right.$ S]methionine added for the last $6 \mathrm{~h}$ (G. S. Greenwald \& S. K. Roy, unpublished). In these circumstances, the pattern of protein synthesis is similar to that observed after $12 \mathrm{~h}$ of incubation, again attesting to the viability of the primordial follicles. The primordial follicles are also surprisingly active, albeit much less so than mature oocytes; they are certainly not inert and in a state of suspended animation. The nature of the proteins synthesized by the primordial follicles is unknown, although Fig. 8 shows that the primordial oocytes had little in common with somatic cells but had a number of similarities with oocytes of antral follicles. This points to very little somatic contamination of the primordial follicle preparations.

In summary, a method for enzymic dissection and separation of pig primordial follicles has been developed which should open new vistas into the factors regulating this important and enigmatic stage of folliculogenesis.

Supported in part by a grant from NIH (HD 00596) to G.S.G. We thank Mr Nigel Miller for performing the cell sorting.

\section{References}

Adams, E.C. \& Hertig, A.T. (1964) Studies of guinea pig oocytes. I. Electron microscopic observations on the development of cytoplasmic organelles in oocytes of primordial and primary follicles. J. Cell Biol. 21, $397-427$.

Baca, M. \& Zamboni, L. (1967) The fine structure of human follicular oocytes. J. Ultrastruct. Res. 19, $354-381$.

Bonner, W.M. \& Laskey, R.A. (1974) A film detection method for tritium-labelled proteins and nucleic acids in polyacrylamide gels. Eur. J. Biochem. 46, 8388.
Dufour, J.J., Fahmy, M.H. \& Flipot, P.M. (1985) Follicular development during the prepubertal period of different morphological types of ovaries in Hampshire and Yorkshire gilts fed two planes of nutrition. $J$. Anim. Sci. 61, 1201-1210

Gosden, R.G. \& Telfer, E. (1987) Numbers of follicles and oocytes in mammalian ovaries and their allometric relationships. J. Zool., Lond. 211, 169-175.

Gougeon, A. \& Chainy, G.B.N. (1987) Morphometric studies of small follicles in ovaries of women at different ages. J. Reprod. Fert. 81, 433 442. 
Laemmli, U.K. (1970) Cleavage of structural proteins during the assembly of the head of the bacteriophage $\mathrm{T}_{4}$. Nature, Lond. 227, 680-685.

Meistrich, M. (1983) Experimental factors involved in separation by centrifugal elutriation. In Cell Separation: Methods and Selected Applications, vol. 2, pp. 33-6I. Eds T. G. Pretlow \& T. P. Pretlow. Academic Press, New York.

Moor, R.M., Osborn, J.C., Cran, D.G. \& Walters, D.E. (1981) Selective effects of gonadotrophins on cell coupling, nuclear maturation and protein synthesis in mammalian oocytes. J. Embryol. exp. Morph. 61, $347-365$.

Parkening, T.A. \& Cisneros, P.L. (1988) Fertilization of Chinese hamster ova in vitro and in vivo and their subsequent development in culture. Biol. Reprod. 39, $409-418$.

Roy, S.K. \& Greenwald, G.S. (1988) In vitro effects of follicle-stimulating hormone, luteinizing hormone and prolactin on follicular deoxyribonucleic acid synthesis in the hamster. Endocrinology 122, 952-958.

Received 21 February 1989 